\title{
Creativity in Primary Education: The Role of Multimedia
}

\author{
Dr. G. Tsayang and Mr. D.M.Totev \\ Faculty of Education, Gaborone
}

\begin{abstract}
$\underline{\text { Abstract }}$
Creativity is very pertinent to both individual and societal growth and therefore it must be enhanced in the education systems. .The Botswana National Vision, Vision 2016 states that by 2016, the education system must have developed an informed, educated and creative nation.. It is noted that Multi-media enhances creativity particularly in young people and therefore must be enhanced at all cost. It is further noted that the conventional understanding of multi-media is too limited if it does not recognize that sound culture is a pre-requisite for sound creativity. The paper therefore argues that in order to achieve universal basic and quality education we must consider using even the indigenous multi-media (culture based) to reach even the most modern technologically disadvantaged learners in order to enhance their creativity. Deliberate efforts must be taken by governments to infuse the culture based ways of enhancing creativity into their school syllabi.
\end{abstract}

\section{Introduction}

Creativity plays a central role in education and especially in Primary education, because of its fundamental nature and great importance for life.

The major studies on creativity could be summarized as follows:

- Relationship between creativity and intelligence [1]

- Measurement of the creative potential [2]

- Methods to stimulate creative behaviour (Osborn-Parnes Creative Problem Solving) [3]

- Relationship between creativity and instruction [4]

The commonly accepted definition of creativity has three parts:

- Creativity is a complex process, subject to studies by Behavioral Psychology, Social Psychology, Psychometrics, Cognitive Science, Artificial Intelligence, Philosophy, Economics, Business and Management, etc.

- Creativity is an interpretation of past knowledge and experience in a new way

- Enrichment of the existing knowledge base

George Keller expressed this definition as “......., consists largely of re-arranging what we know in order to find out what we do not know.".

Some students of creativity consider the creative process as a five-step one: [5]

- Fact-finding

- Problem-finding

- Idea-finding

- Solution-finding

- Acceptance-finding

Certain cognitive characteristics contribute to one's creative behaviour: [6]

- Fluency 
- Flexibility

- Visualisation

- Imagination

- Expressiveness

- Openness

Such skills could be learned or they may be situational. Fluency is related to the number of meaningful responses to a challenge, while flexibility reflects the diversity of the responses provided. These features are involved in the psychometric study of creativity too. [7]

In the global economy creativity is becoming more and more important, a tendency that underlies the necessity of stimulating and encouraging creative behaviour. Nicherson analises the various creativity techniques, developed by academia and industry as follows: [8]

- Establishing purpose and intention

- Building basic skills

- Encouraging acquisitions of domain-specific knowledge

- Stimulating curiosity and exploration

- Building motivation, especially internal motivation

- Encouraging confidence and a willingness to take risks

- Focusing on mastery and self-competition

- Promoting supportable beliefs about creativity

- Providing opportunities for choice and discovery

- Developing self-management (meta-cognitive skills)

- Teaching techniques and strategies for facilitating creative performance

- Providing balance

Some scholars consider conventional educational systems as not providing conducive environment for the development of creative thinking. This is the main reason why special attention is paid to pre-schools and primary schools in order to rectify such a situation.

This presentation treats the educational system as a whole and tries to explore how it can stimulate creativity at all levels - pupils, teachers and administration. Such an approach calls for a wider interpretation of the Multimedia concept, an essential tool to enhance creativity. The advantages of the conventional application of multimedia techniques are well proven by many researchers. Recently, a study on the implementation of a powerful tool for interactive training [9] could illustrate the importance of the conventional multimedia to creativity. [10], Fig 1. 


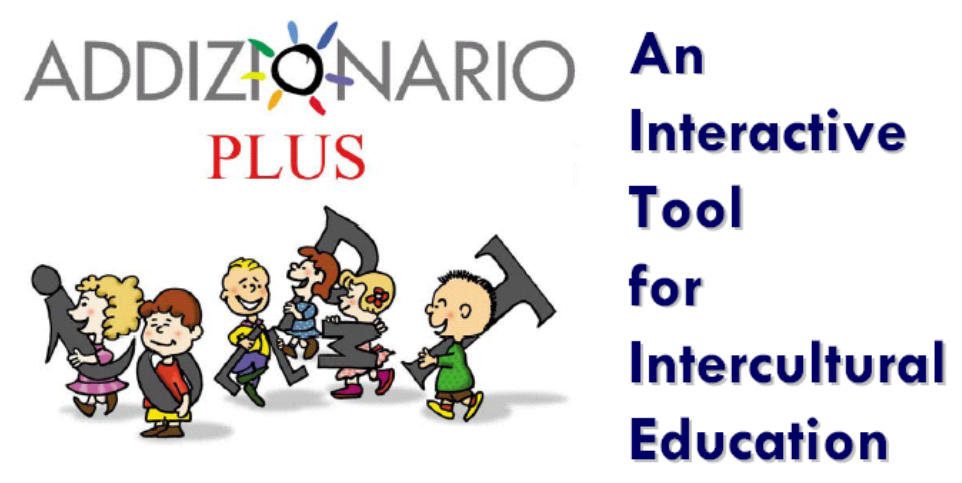

Giovanna Turrini, Paola Baroni, Alessandro Paccosi Istituto di Linguistica Computazionale del CNR - Pisa - ITALY

[aiovanna.turrini/paola.baroni/alessandro.paccosi]@ilc.cnr.it

Fig. 1

On Fig. 2 some of the basic communication tools available to the kids are shown:

\section{My Dictionary "Construct" menu}

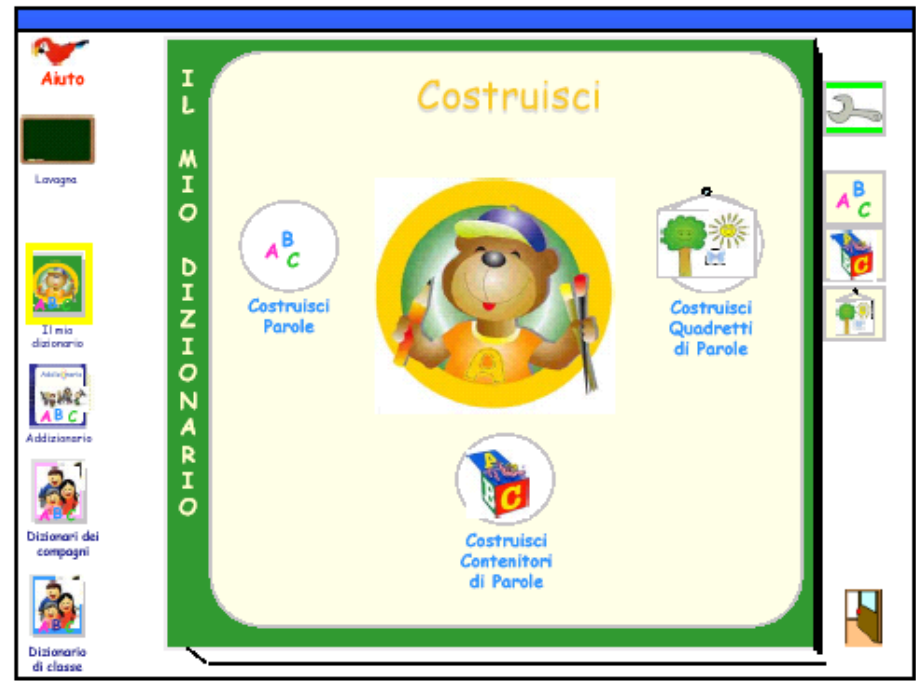

Fig. 2

The following table, Fig. 3, summarises some of the main results of the study: 


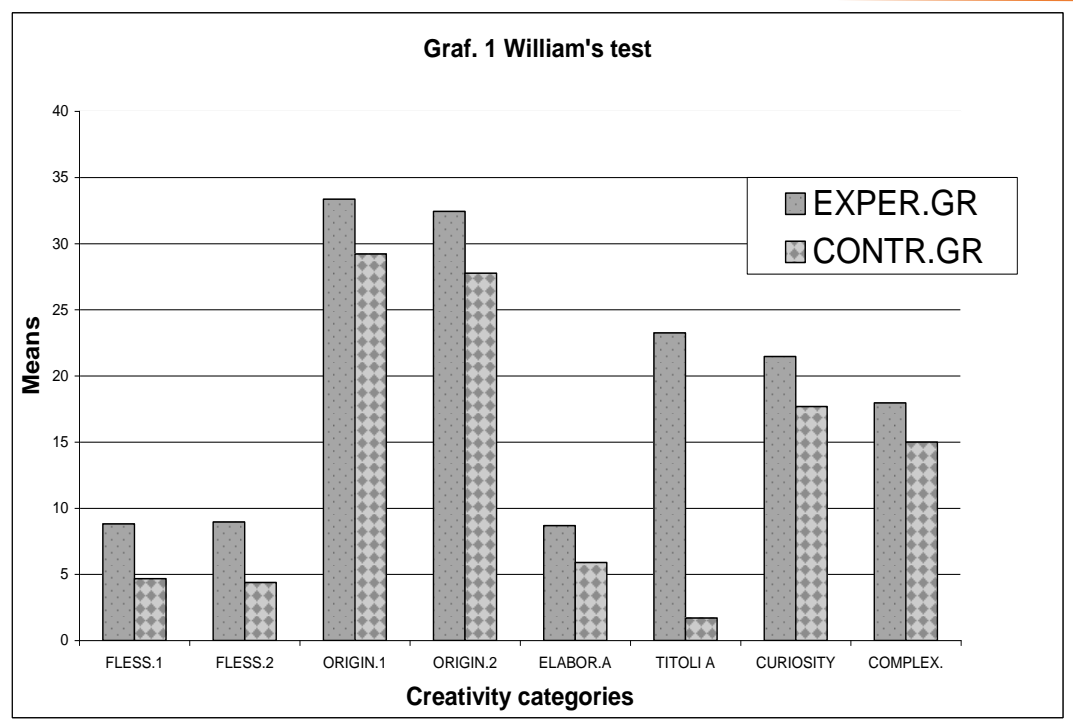

Fig. 3

Some other authors consider creativity from a philosophical point of view and try to define the major social and political factors that contribute to its stimulation [11], Fig. 4 (Prof. Hiwaki's Conceptual Framework). Culture plays a significant role in enhancing creativity. He asserts that Sound creativity results from Sound culture.

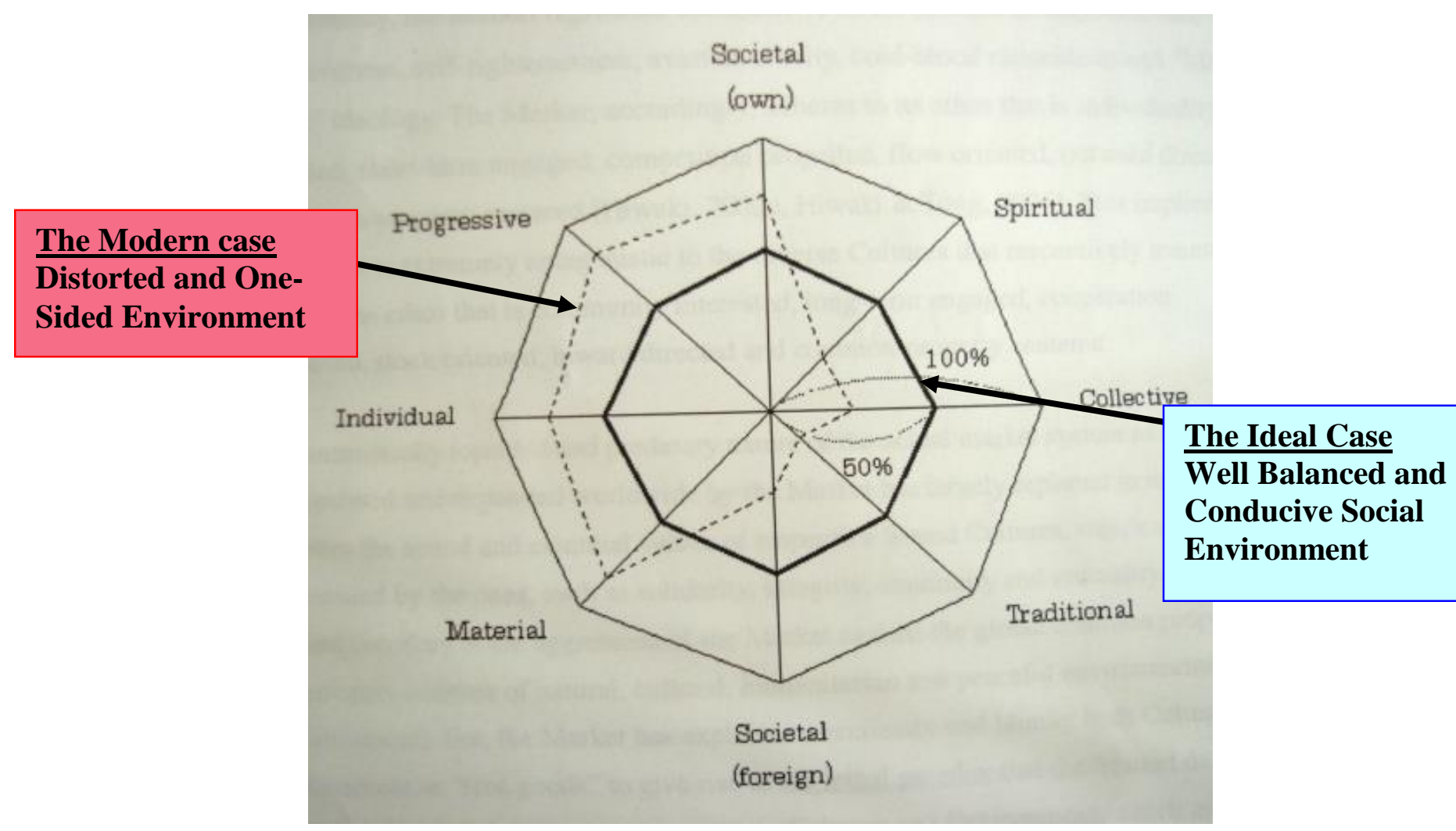

Fig. 4 


\section{Culture as basis for Sound Creativity in basic Education}

Botswana has as many cultures as there are societal groups. In many cases cultures are almost similar to one another. Culture is manifested in various attributes such as language, food, dress, techonolgy, entertainment and customs just to mention a few. These multicultural set ups are found within the societies as Batswana live side by side with each other from various backgrounds. The multiculturalism found in Botswana communities is replicated in the schools where one finds in any primary schools in particular, children from Botswana as a country and those from outside, those from various ethnic as well as language groups.

Despite the divergent cultures in the country, Botswana has as one of the aims of education, creation of a creative and innovation nation. As indicated in Vision 2016, the education system will empower citizens to become the best producers of goods and services. The country's education system aims at producing citizens who have entrepreneurial aptitudes and who will therefore be able to create employment. The ultimate goal of education is therefore to produce citizens who will be able to adapt to the changing needs of the country and the world at large as the world around them is not static and is very uncertain, therefore citizens who are creative.

It is the contention of the authors that providing an enabling environment as early as at primary education level is the basic foundation for creativity. All normal children have the potential which they are born with and it is important for such potential to be triggered to be live. It is the contention of the authors of the paper that sound creativity in learners is based on sound culture.

Research has found out that children who are exposed to multi-media perform better than those who are not (Miazza, Zanetti, Renati, and Pagnin (2006) Turrini, Baroni, Paccosi (2006). A comparision is made between multi-media in the conventional sense of using modern technology in the likes of a computer in particular and non use of the modern technology. This paper argues that, the conventional conception of multi-media is limiting because it excludes the traditional indigenous way in which people communicated then and now. The early indigenous people survived, produced things and lived on because they had their own technology. They were able to be creative because of their art, skill, and craft. They had their own techniques or methods of performing specialized tasks. All these reflected their ability to be creative. They did not need a computer to be creative. In other words, ICT is not a pre-requisite to creativity but an enhancement of it. A computer is, of course, an important tool to enhance that natural creativity but not a replacement of culture as a source of creativity. Therefore, indigenously, there has always been traditional multimedia which the authors feel is not fully explored to benefit those who may not be directly exposed to modern multi-media. If this is not explored, we cannot think or dream of universal education for all.

The traditional or the cultural way of communicating in its multi-faceted ways is hardly regarded as part of multi-media let alone taken on board in modern learning environments. It is further argued that, creativity does not come with the advent of modern technology, it 
has always been there with the existence of humankind hence they were able to survive various conditions. It is further argued that learning and creativity are enhanced by experiential circumstances. People learn better what they live, which is culture and therefore, if the traditional lives which we are sure, offered creativity were to be taken on board in the modern learning environments, they would comfortably complement modern technology and enhance creativity. In particular, the authors feel, where modern technology is not available it would be wise to utilize traditional indigenous ways of knowing and ways of being creative as a result. This implies taking on board what Prof. Hiwaki [12] refers to as using Sound Culture to enhance Sound Creativity.

If the words multi- and media are interrogated further, and Webster Dictionary meaning is any thing to go by then the word itself is not fully interpreted if its meaning is mainly confined to the use of modern technology. This further interrogation can be seen to mean the following:

Multi as in 'many' or 'more than one'.

Media as in a 'means of communication'.

According to Webster Comprehensive Dictionary, Multi-Media means, "relating to or using two or more media, especially a combination apprehended by different senses as sight and hearing" (p835) [13].

When looking at the literal meaning of the word itself, it can be argued that indeed every culture or every society had its own way of communicating which is multi-faceted and comprehended by the different senses as sight and hearing, hence every society can be said to have its own multi-media even before the advent of modern multi-media.

The narrow conception of multi-media is indeed limiting with regards to the training of and understanding by the teachers who must stimulate children creativity. The concept of multi-media in the modern or conventional context, it is argued, appears to be perceived as alien by teachers as it is associated with modern technology.

It must be noted that indeed multi-media is not a new concept to Botswana and the Batswana and the indigenous world as a way of communication and encouraging creativity amongst the young ones. One thing that is disturbing is that the indigenous people have not and do not respect what the authors of this article refer to as indigenous multi-media, their culture which is a basis for creativity. The colonial mentality has eroded the pride they should have about their own culture which is a basis for Sound Creativity. This indigenous multi-media is indeed very rich, in abundance and accessible to everyone to encourage the young ones to be creative. It is the most relevant and would be better understood by most rural children who are not exposed to modern multi-media.. The authors see the traditional games and other indicators of the Botswana culture as indigenous multi-media which can enhance children's creativity if utilized by the teachers in the same way that they regard modern technology. For instance, there are a number of games whose role was not only to provide entertainment but also to develop the creativity and critical thinking in the young minds

Some of these games are as follows: Mmele, Morabaraba, Diketo, Fig. 5. 

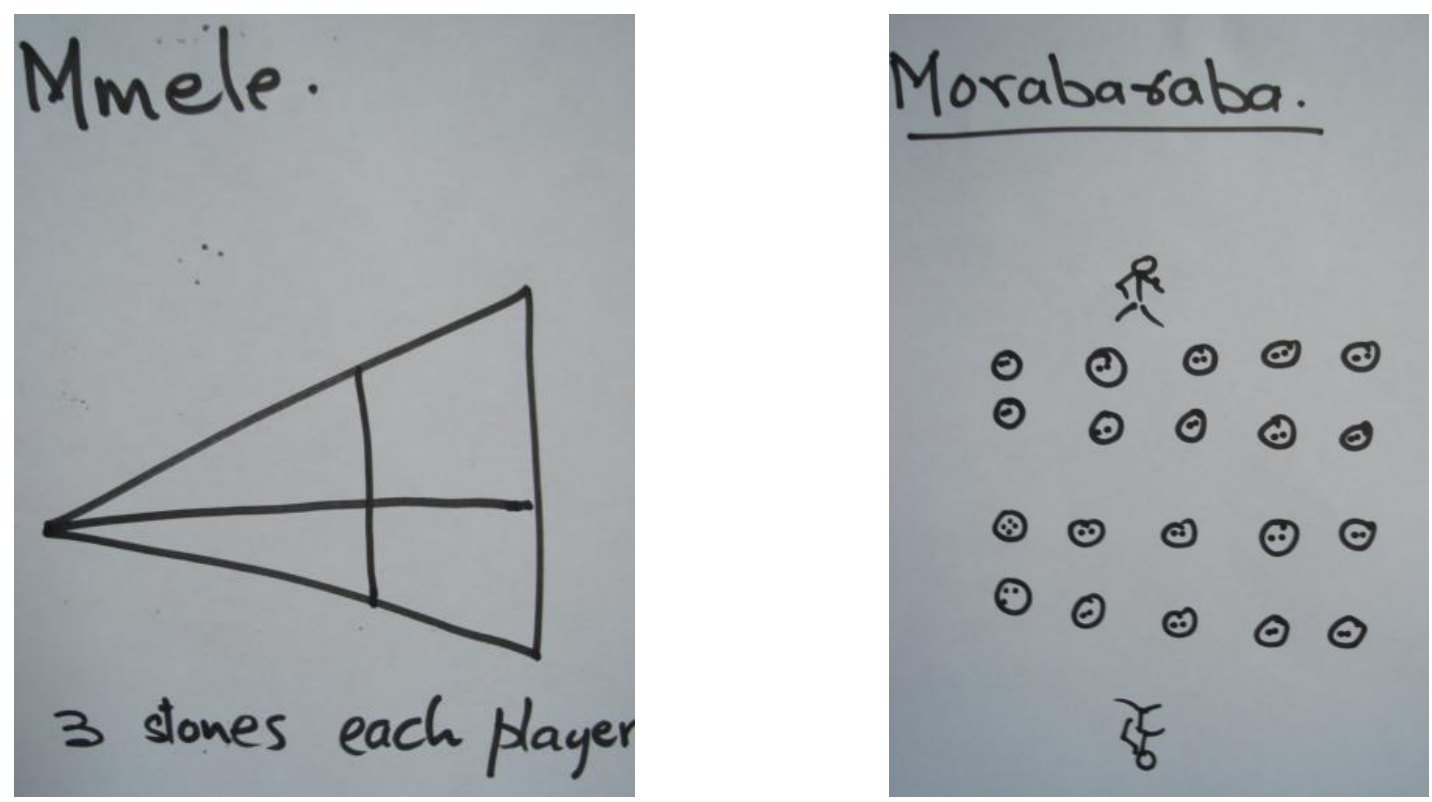

Fig. 5

There also are, as part of the culture story telling, and riddles, which were performed by young ones as they relaxed while looking after cattle and goats or in the evening passing the time away before going to bed. These riddles and story telling in particular were used to test each other's thinking capacities and encouraged creativity.

It is argued that indeed those not exposed to multi-media are more likely not to perform like those exposed. The point of contention is that the concept of multi-media should be enhanced and treated in a broader way to accommodate the indigenous cultural values and create a conducive and balanced environment for sound creativity. Where there are no computers and modern technology, there is the other component of the enhanced multimedia which is sound culture which if explored can enhance creativity. It is emphasized therefore that if vision 2016 and achievement of universal basic education for all is to be achieved, and access to educational resources is to be achieved, there is need to explore these other forms of multi-media, the indigenous traditional multi-media and utilize it to enhance creativity by those children in areas far from the modern technology.

\section{Recommendations}

$>$ It is therefore suggested that for teachers to recognize the indigenous multi-media as equally important, they need to be sensitized to this indigenous aspect of multimedia.

Teachers must be made to appreciate that which is traditional and therefore context based and indeed readily available to everyone as a learning resource base

> UNESCO and other Educational Organisations could be asked for assistance to help infuse traditional cultural attributes into school curriculum to enhance creativity. 
The concept of multi-media should be explored further to include any other form of knowledge or experience that could be beneficial to the creativity of pupils.

$>$ The education systems must infuse indigenous multi-media in curriculum.

\section{References}

1. Guiford, J.P. (1950). Creativity. American Psychologist, 5, 444-454.

2. Torrance, E. (1979). The Search for Satori and Creativity. Buffalo, NY: Bearly Ltd.

3. Parnes, S.J. (1967). Creative Behavior Guidebook. New York: Scribners.

4. Taylor, C., Williams, F. (1966). Instructional Media and Creativity. New York: Wiley

5. VanGundy, A.B. (1987). Creative problem Solving. New York: Quorum

6. DIP Concepts (2005). http://tip.psychology.org/create.html

7. Guiford, J.P. (1967). The Nature of Human Intelligence

8. Nicherson, R.S. (1999). Enhancing Creativity, ed. Sternberg, R.J. Handbook of Creativity. Cambridge University Press.

9. Turrini, G., et.al. (2006). Addizionario Plus: an Interactive Tool for Intercultural Education. ISSEI 2006, University of Malta

10. Miazza, D., et.al. (2006). Supporting the Development of the Thought.

Creative Horizons. ISSEI 2006, University of Malta

11. Hiwaki, K., (2006), Developing Creativity: A Sound Culture for Sound Creativity, ISSEI

2006.

12. Tong, J., et al, (2006), Credibility Trap: Japan Today and China Tomorrow, Human Systems

Management, Vol. 25, No 1, pp.31-50

13. Markwardt A.H., Cassidy, F.G. and McMillanJ.G. (2000) Webster Comprehensive

Dictionary Encyclopedia Edition, Volume One; Chicago, Fergson Publishing Company, 